07

\title{
Микроструктура, упругие и неупругие свойства биоморфных углеродов, карбонизированных с использованием Fe-содержащего катализатора
}

\author{
() T.С. Орлова ${ }^{1,2}$, Б.К. Кардашев ${ }^{1}$, Б.И. Смирнов ${ }^{1}$, A. Gutierrez-Pardo ${ }^{3}$, J. Ramirez-Rico ${ }^{3}$ \\ ${ }^{1}$ Физико-технический институт им. А.Ф. Иоффре РАН, \\ Санкт-Петербург, Россия \\ ${ }^{2}$ Санкт-Петербургский национальный исследовательский университет \\ информационных технологий, механики и оптики, \\ Санкт-Петербург, Россия \\ ${ }^{3}$ Dpto Fisica de la Materia Condensada-ICMS, Universidad de Sevilla, \\ Sevilla, Spain \\ E-mail: orlova.t@mail.ioffe.ru
}

(Поступила в Редакцию 28 апреля 2016 г.)

Исследованы микроструктура и амплитудные зависимости модуля Юнга $E$ и внутреннего трения (логарифмического декремента $\delta$ ), а также микропластические свойства у биоуглеродных матриц $\mathrm{BE}-\mathrm{C}(\mathrm{Fe})$, полученных карбонизацией дерева бука при температурах $T_{\text {carb }}=850-1600^{\circ} \mathrm{C}$ в присутствии железосодержащего катализатора. Методами рентгеноструктурного анализа и просвечивающей электронной микроскопии показано, что использование Fе-катализатора при карбонизации с $T_{\text {carb }} \geq 1000^{\circ} \mathrm{C}$ приводит к появлению объемной графитовой фазы в виде наноразмерных объемных графитовых включений в квазиаморфной матрице, объемная доля и размер которых увеличиваются с повышением $T_{\text {carb. }}$ Выявлена корреляция полученных зависимостей $E\left(T_{\text {carb }}\right)$ и $\delta\left(T_{\text {carb }}\right)$ с эволюцией микроструктуры при увеличении $T_{\text {carb }}$. Обнаружено, что величина $E$ определяется главным образом долей кристаллической фазы в аморфной матрице: нанокристаллической фазы при $T_{\text {carb }}<1150^{\circ} \mathrm{C}$ и объемной графитовой фазы при $T_{\text {carb }}>1300^{\circ} \mathrm{C}$. Максимальные значения $E=10-12 \mathrm{GPa}$ достигнуты для образцов с $T_{\text {carb }} \approx 1150$ и $1600^{\circ} \mathrm{C}$. Показано, что микропластичность проявляется лишь у биоуглеродов с $T_{\text {carb }} \geq 1300^{\circ} \mathrm{C}$ (при достижении значительного объема графитовой фазы), при этом условный предел микротекучести понижается с увеличением суммарного объема введенной мезопористости (площади свободной поверхности).

Работа выполнена при частичной поддержке РФФИ (грант № 14-03-00496) и Программы Президиума РАН $(\Pi-20)$.

\section{1. Введение}

Различные пористые углеродные материалы традиционно используются в качестве материалов для электродов, что обусловлено их химической стойкостью к различным электролитам, широкой областью рабочих температур, хорошими характеристиками электро- и теплопроводности [1-5]. Важными структурными параметрами углеродных материалов, необходимыми для использования их в качестве электродов к суперконденсаторам, являются взаимосвязанная мезопористость (с размерами пор 2-50 nm, благоприятными для проникновения электролита), обеспечивающая большую свободную поверхность, а также микропористость, поскольку соотношение мезо/микропористости может значительно влиять на величину удельной емкости в электролите [6].

В последнее время биоморфные углеродные матрицы, получаемые карбонизацией натурального дерева или прессованной микрофибры, рассматриваются как перспективные материалы для применения в качестве электродов, поскольку они обладают многоуровневой взаимосвязанной системой пор с достаточно жестким каркасом [7-11], хорошей электро- $[12,13]$ и теплопроводностью [14-16], а также не требуют использования связующих компонентов для изготовления из них электродов в отличие от порошковых углеродов. Для некоторых типов исходной древесины открытая природная пористость в биоуглеродах может достигать $75 \%$. При этом имеет место бимодальная структура канальных пор, вытянутых вдоль направления роста дерева, а именно существуют поры малых размеров с диаметром 3-9 $\mu \mathrm{m}$ и больших размеров с диаметром в пределах 20-200 $\mathrm{m}$ в зависимости от типа исходной древесины. Однако для использования биоуглеродов в качестве электродов необходимо введение в них мезопористости, сопровождаемой значительным увеличением свободной поверхности. Успешные попытки введения такой мезопористости были предприняты в работах $[17,18]$. За счет использования катализаторов на основе переходных металлов $\mathrm{Ni}$ и $\mathrm{Fe}$ было достигнуто увеличение площади свободной поверхности в $\sim 60$ и $\sim 180$ раз соответственно. Кроме того, применение данных катализаторов при определенных температурах карбонизации $T_{\text {carb }}$ приводило к частичной графитизации био- 
углеродов $[17,19,20]$, в результате которой повышались электро- и теплопроводность данных материалов [2123]. В результате на биоуглеродах, полученных с использованием Fе-содержащего катализатора была достигнута относительно высокая электроемкость > $100 \mathrm{~F} / \mathrm{g}$, сравнимая со значениями для ряда коммерческих углеродных материалов [17]. Для потенциального использования высокопористых биоуглеродных материалов важными являются также характеристики их упругих свойств, прочности и микропластичности. В наших предыдущих работах на биоуглеродах, карбонизированных без катализатора $[24,25]$ и с использованием $\mathrm{Ni}$-содержащего катализатора $[26,27]$ с температурой карбонизации в широком интервале $800-1600^{\circ} \mathrm{C}$, было показано, что упругие и механические свойства сильно зависят как от параметров пористой структуры, так и от микроструктуры самого биоуглеродного каркаса.

В настоящей работе мы продолжаем серию исследований влияния каталитической графитизации на физико-механические свойства биоуглеродных материалов. Впервые исследуются упругие и микропластические свойства биоуглеродов, полученных карбонизацией древесины бука при различных температурах в присутствии $\mathrm{Fe}$-содержащего катализатора, в сопоставлении с их микроструктурными особенностями. Полученные данные по особенностям микроструктуры, упругим и неупругим свойствам сравниваются с подобными характеристиками образцов, приготовленных в тех же условиях с использованием Ni-содержащего катализатора (система образцов $\mathrm{BE}-\mathrm{C}(\mathrm{Ni})$ ) [26] или вообще без катализатора (система образцов ВЕ-C) [24].

\section{2. Образцы и экспериментальная методика}

Исследовались образцы биоуглерода, полученного карбонизацией древесины бука при различных значениях температуры карбонизации $T_{\text {carb }}$ в области $850-1600^{\circ} \mathrm{C}$ в присутствии Fе-содержащего катализатора. Куски древесины бука размером $75 \times 15 \times 15 \mathrm{~mm}$ предварительно высушивались в печи для устранения из пор остаточной влаги, а затем помещались в $3 \mathrm{M}$ раствор хлорного железа $\left(\mathrm{FeCl}_{3}\right)$ в изопропаноле для заполнения им пор. Для обеспечения заполнения раствором всего пространства пор воздух из пор предварительно откачивался путем помещения образца в вакуумную камеру. Образцы выдерживались в растворе в течение $2 \mathrm{~h}$, затем высушивались при небольшом подогреве до момента полного высыхания, который контролировался по изменению веса прекурсора. Пиролиз осуществлялся в потоке инертного газа (азота чистоты 99.999\%). Нагрев проводился со скоростью $1^{\circ} \mathrm{C} / \mathrm{min}$ до $500^{\circ} \mathrm{C}$, затем со скоростью $5^{\circ} \mathrm{C} / \mathrm{min}$ до температуры $T_{\text {carb }}(850,1000$, $1150,1300,1400,1500$ и $\left.1600^{\circ} \mathrm{C}\right)$, при которой образец выдерживался в течение $30 \mathrm{~min}$ и затем охлаждался со скоростью $5^{\circ} \mathrm{C} / \mathrm{min}$. Такой температурный режим пиролиза позволял избежать трещинообразования. После пиролиза остаточное железо устранялось путем промывания образцов в концентрированной кислоте $\mathrm{HNO}_{3}$ $(67 \%$, Panreac) в течение $2 \mathrm{~h}$ с последующим промыванием в ацетоне до достижения нейтрального значения $\mathrm{pH}$ и сушкой в печи. Данный метод получения графитизированных биоуглеродов подробно описан в [17]. Далее образцы биоуглерода бука, карбонизированные при определенной температуре $T_{\text {carb }}$ с использованием $\mathrm{Fe}-$ содержащего катализатора и затем химически обработанные для удаления остаточного железа, будем относить к системе образцов $\mathrm{BE}-\mathrm{C}(\mathrm{Fe})$ и обозначать BE-C- $T_{\text {carb }}(\mathrm{Fe})$, т. е., например, BE-C-850(Fe) - биоуглерод, полученный карбонизацией дерева бука при $T_{\text {carb }}=850^{\circ} \mathrm{C}$ в присутствии Fе-катализатора.

Структура карбонизированных образцов исследовалась методами рентгеновской дифрактометрии (D8 Advance, Bruker) и просвечивающей электронной микроскопии (Philips CM-200).

Образцы для акустических исследований имели форму прямоугольных параллелепипедов с квадратным поперечным сечением площадью $\sim 16 \mathrm{~mm}^{2}$ и длиной $\sim 20 \mathrm{~mm}$, при этом длинная сторона образцов была ориентирована вдоль ростовых волокон исходного дерева. Для измерений модуля Юнга $E$ и декремента ультразвуковых колебаний $\delta$ использовался метод составного вибратора. В образцах возбуждались продольные резонансные колебания на частоте около $100 \mathrm{kHz}$. Измерялись модуль Юнга $E$ и декремент ультразвуковых колебаний $\delta$ в зависимости от амплитуды акустических колебаний $\varepsilon$, которая изменялась в пределах от $\sim 10^{-7}$ до $2 \cdot 10^{-4}$. Подробное описание метода можно найти в [28]. Для измерения амплитудных зависимостей $E(\varepsilon)$ и $\delta(\varepsilon)$ акустическая система (исследуемый образец и кварцевый преобразователь) помещалась в вакуумную камеру, из которой воздух откачивался до величины давления $\sim 10^{-3} \mathrm{~mm} \mathrm{Hg}$. Затем измерялись амплитудные зависимости модуля Юнга $E$ и декремента $\delta$ при комнатной температуре.

\section{3. Экспериментальные данные и их обсуждение}

3.1. Структурная характеризация образц о в. На рис. 1 показан пример рентгеновских дифрактограмм для биоуглеродных образцов, карбонизированных при различной температуре с использованием железосодержащего катализатора. Как и в случае применения $\mathrm{Ni}$-катализатора [19], использование Fе-катализатора при $T_{\text {carb }} \geq 1000^{\circ} \mathrm{C}$ приводит к формированию графитизированной фазы, о чем свидетельствует появление на рентгенограмме сильного пика (002) при $2 \theta=26.6^{\circ}$ (рис. 1). При меньших температурах карбонизации использование Fе-катализатора не приводило к формированию заметной доли графитовой фазы. 
Исследование степени упорядочения структуры исследуемых биоуглеродов, полученных с использованием $\mathrm{Fe}$-содержащего катализатора, было проведено методом рамановской спектроскопии в работе [22], в которой на основе анализа рамановских спектров была определена степень кристалличности (относительное содержание графитовой фазы) как функция $T_{\text {carb }}$. Было показано, что при повышении $T_{\text {carb }}$ от 850 до $1150^{\circ} \mathrm{C}$ доля кристаллитов типа графита возрастает очень незначительно: от $\sim 23$ до $\sim 25 \%$, в то время как при дальнейшем увеличении $T_{\text {carb }}$ она увеличивается со значительно большей скоростью и при $T_{\text {carb }}=1600^{\circ} \mathrm{C}$ достигает более $60 \%$.

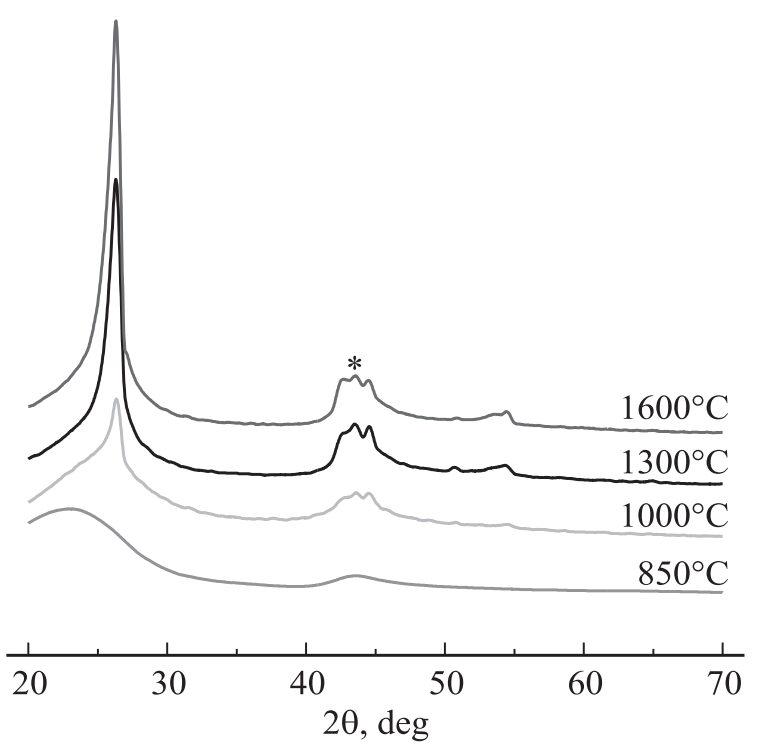

Рис. 1. Картины рентгеновской дифракции для биоуглеродных образцов, карбонизированных при различных температурах в присутствии Fе-содержащего катализатора. Звездочкой отмечены пики, относящиеся к остаточному железу после травления образцов в $\mathrm{HNO}_{3}$.

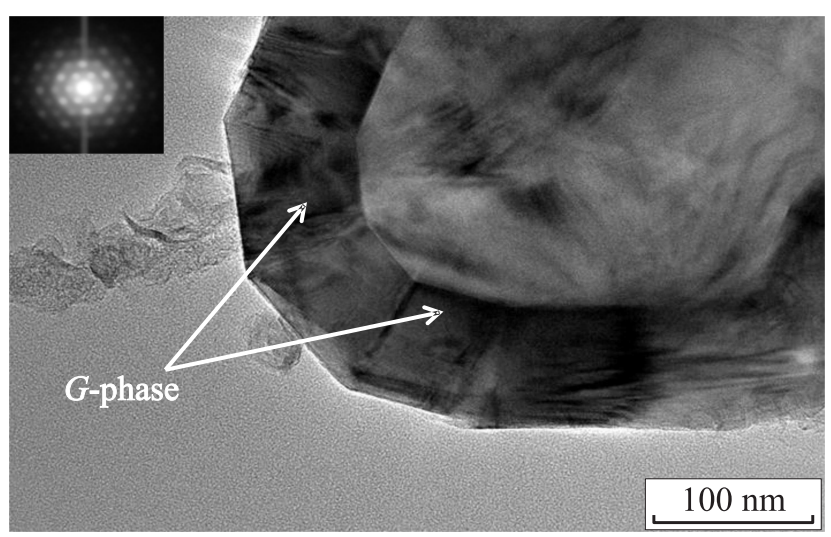

Рис. 2. Типичное микроструктурное изображение, полученное методом просвечивающей электронной микроскопии для биоуглерода, карбонизированного при $T_{\text {carb }}=1600^{\circ} \mathrm{C}$ в присутствии Fе-катализатора. Стрелками показана графитовая фаза $(G$-фаза). На вставке - селективная электронная дифракция от $G$-фазы.
Характеристики мезопористости биоуглеродов $\mathrm{BE}-\mathrm{C}(\mathrm{Fe})$ и $\mathrm{BE}-\mathrm{C}(\mathrm{Ni})$, определенные по методу ВЕТ $[17,18]$

\begin{tabular}{c|c|c|c|c}
\hline Образец & $\begin{array}{c}T_{\text {carb }}, \\
{ }^{\circ} \mathrm{C}\end{array}$ & $\begin{array}{c}\text { Площадь } \\
\text { поверхности } \\
\text { пор, } \mathrm{m}^{2} / \mathrm{g}\end{array}$ & $\begin{array}{c}\text { Средний } \\
\text { размер } \\
\text { поры, } \mathrm{nm}\end{array}$ & $\begin{array}{c}\text { Объем } \\
\text { пор, } \\
\mathrm{cm}^{3} / \mathrm{g}\end{array}$ \\
\hline $\mathrm{BE}-\mathrm{C}(\mathrm{Fe})$ & 1000 & 370 & 2.6 & 0.24 \\
& 1300 & 217 & 3.6 & 0.21 \\
$\mathrm{BE}-\mathrm{C}(\mathrm{Ni})$ & 1600 & 167 & 3.6 & 0.15 \\
& 1000 & 121 & 6.3 & 0.19 \\
& 1300 & 72.6 & 6.8 & 0.12 \\
& 1600 & 53.7 & 7.5 & 0.10
\end{tabular}

Исследование тонкой структуры введенной графитовой фазы, проведенное методом просвечивающей электронной микроскопии, показало, что графитовая фаза образуется путем наслоения турбостатического графита вокруг частиц $\mathrm{Fe}$ [17]. После устранения химическим путем частиц $\mathrm{Fe}$ графитовая фаза представляет собой полые наноразмерные сферообразные включения, размер которых не превышает $200 \mathrm{~nm}$ даже при максимальном значении $T_{\text {carb }}=1600^{\circ} \mathrm{C}$ (рис. 2). Это принципиально отличает микроструктуру образцов $\mathrm{BE}-\mathrm{C}(\mathrm{Fe})$ от микроструктуры системы биоуглеродов $\mathrm{BE}-\mathrm{C}(\mathrm{Ni})$, полученных с использованием катализатора на основе $\mathrm{Ni}$, у которых при $T_{\text {carb }} \geq 1450^{\circ} \mathrm{C}$ формировались глобулы графита микронных размеров [19].

Использование Fe-катализатора не влияло на макропористую структуру биоуглеродных образцов: для всех температур карбонизации она оставалась подобной и характеризовалась наличием канальных пор, ориентированных вдоль направления роста дерева и имеющих бимодальную структуру: поры малого $(3-7 \mu \mathrm{m})$ и большого $(22-38 \mu \mathrm{m})$ диаметров. Суммарный объем таких макроскопических пор у образцов составлял $65 \pm 5 \%$ [6]. Однако, использование Fе-катализатора приводило к появлению мезо- и микропористости и, как следствие, значительному увеличению площади свободной поверхности $A$. Характерные параметры этой дополнительной пористости: суммарный объем и средний размер пор, а также величина площади свободной поверхности $A-$ представлены в таблице по данным исследований методом Брунауэра-Эммета-Теллера (BET), ранее проведенных на этих образцах в $[17,18]$.

3.2. Упругие и неупругие свойства. На рис. 3 показаны зависимости от температуры карбонизации модуля $E(a)$ и декремента $\delta(b)$, измеренные в вакууме после откачки воздуха для биоуглеродных матриц BE$\mathrm{C}(\mathrm{Fe})$, полученных карбонизацией бука в присутствии Fe-содержащего катализатора (кривые 1 ). Отметим, что измеряемые (действующие) значения $E$ и $\delta$ определялись исходя из полного сечения образца, включающего и площадь пор. Там же для сравнения приведены зависимости $E\left(T_{\text {carb }}\right)$ и $\delta\left(T_{\text {carb }}\right)$, полученные нами ранее для биоуглеродных матриц бука, карбонизированных в тех 

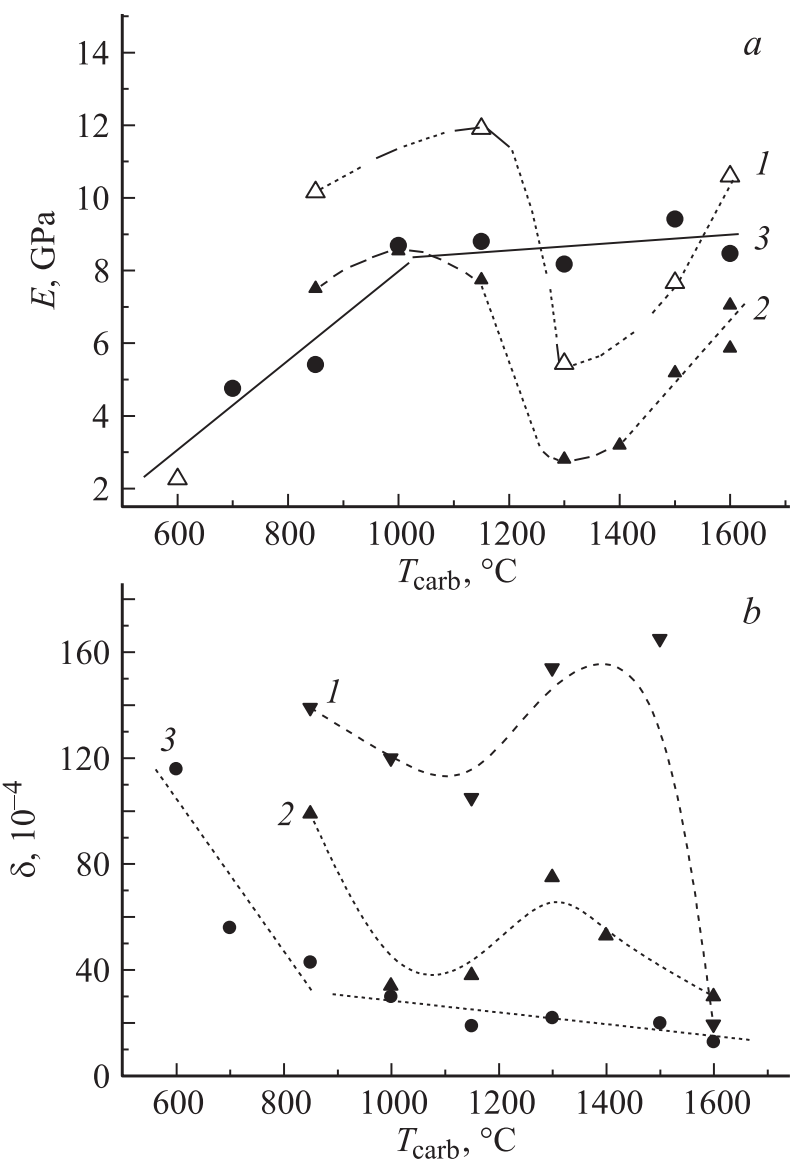

Рис. 3. Зависимости модуля Юнга $E(a)$ и декремента $\delta(b)$ для биоморфных углеродных образцов от температуры их карбонизации $T_{\text {carb }} 1$ - серия образцов $\mathrm{BE}-\mathrm{C}(\mathrm{Fe})$ (данные настоящей работы), 2 - образцы $\mathrm{BE}-\mathrm{C}(\mathrm{Ni})$ [26], 3 - образцы BE-C [24].

же условиях c Ni-содержащим катализатором [26] (кривые 2) и без катализатора [24] (кривые 3). Для образцов $\mathrm{BE}-\mathrm{C}$ зависимости $E\left(T_{\text {carb }}\right)$ и $\delta\left(T_{\text {carb }}\right)$ фактически состоят из двух линейных областей: при росте $T_{\text {carb }}$ до $\sim 1000^{\circ} \mathrm{C}$ наблюдается быстрое увеличение $E$ и уменьшение $\delta$, затем при $T_{\text {carb }}>1000^{\circ} \mathrm{C}$ эти изменения происходят существенно медленнее (рис. $3, a, b$, кривые 3 ). Такое поведение коррелирует с увеличением доли нанокри-

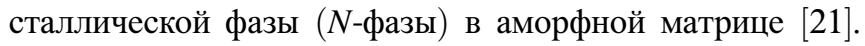
Быстрое изменение $E$ и $\delta$ с температурой в интервале $T_{\text {carb }}<1000^{\circ} \mathrm{C}$ связывается с ростом доли $N$-фазы в аморфной матрице, в то время как при $T_{\text {carb }}>1000^{\circ} \mathrm{C}$ упругие свойства определяются уже практически сформировавшейся нанокристаллической фазой [24]. Следует отметить, что в области температур $T_{\text {carb }}=900-1000^{\circ} \mathrm{C}$ наблюдается известный переход изолятор-сильно разупорядоченный металл [12,13], а также происходит изменение поведения тепловых свойств биоуглеродов, карбонизированных на основе натуральной древесины $[14,15]$.

Примечательно, что зависимости $E\left(T_{\text {carb }}\right)$ для серий образцов $\mathrm{BE}-\mathrm{C}(\mathrm{Fe})$ и $\mathrm{BE}-\mathrm{C}(\mathrm{Ni})$ подобны и демонстриру- ют провал (резкое уменьшение величины $E$ ) в интервале $1150<T_{\text {carb }} \leq 1300^{\circ} \mathrm{C}$, при этом во всем исследованном интервале $T_{\text {carb }}$ величины модуля Юнга в $1.5-2$ раза выше в случае системы $\mathrm{BE}-\mathrm{C}(\mathrm{Fe})$, чем для системы образцов $\mathrm{BE}-\mathrm{C}(\mathrm{Ni})$. Такой характер зависимости $E\left(T_{\text {carb }}\right)$ у частично графитизированных образцов $\mathrm{BE}-\mathrm{C}(\mathrm{Fe})$ и $\mathrm{BE}-\mathrm{C}(\mathrm{Ni})$ никак не коррелирует с увеличением введенной мезопористости и, как следствие, с увеличением свободной поверхности, которые максимальны для $T_{\text {carb }}=1000^{\circ} \mathrm{C}$ и постепенно уменьшаются с повышением $T_{\text {carb }}$ для обеих систем (см. таблицу). В [26] при исследовании системы $\mathrm{BE}-\mathrm{C}(\mathrm{Ni})$ было высказано предположение, что формирование объемной графитовой фазы $\left(G\right.$-фазы) при $T_{\text {carb }} \geq 1000^{\circ} \mathrm{C}$ подавляет формирование $N$-фазы, что приводит к падению значений модуля $E$ в области $1150<T_{\text {carb }} \leq 1300^{\circ} \mathrm{C}$, затем при дальнейшем повышении температуры карбонизации $T_{\text {carb }}>1300^{\circ} \mathrm{C}$ модуль $E$ растет за счет формирования $G$-фазы. Действительно, по данным рамановской спектроскопии [22] в образцах системы $\mathrm{BE}-\mathrm{C}(\mathrm{Fe})$ объем $G$-фазы практически не изменяется при $1000<T_{\text {carb }}<1200^{\circ} \mathrm{C}$ и остается на уровне $23-25$ vol.\%, а затем быстро растет, достигая $\sim 30$ vol. $\%$ при $T_{\text {carb }}=1300^{\circ} \mathrm{C}$ и $\sim 60$ vol. $\%$ при $T_{\text {carb }}=1600^{\circ} \mathrm{C}$. В то же время рентгеноструктурный анализ, проведенный для системы образцов BE-C в [16], показал, что в интервале температур $1000<T_{\text {carb }}<1200^{\circ} \mathrm{C}$ объем нанокристаллической фазы превышает $50 \mathrm{vol} . \%$. Следует также принимать во внимание тот факт, что размер нанокристаллитов в $N$-фазе изменяется от $\sim 12 \AA$ (для кристаллитов типа графита) и $\sim 26 \AA$ (для кристаллитов типа графена) при $T_{\text {carb }}=1000^{\circ} \mathrm{C}$ до $\sim 25$ и $\sim 60 \AA$ соответственно при $T_{\text {carb }}=2400^{\circ} \mathrm{C}$ [29]. В случае же применения Fe-содержащего катализатора формируются графитовые структуры с размерами кристаллитов от $\sim 110 \AA$ у образцов с $T_{\text {carb }}=1000^{\circ} \mathrm{C}$ до $\sim 210 \AA$ для образцов $\mathrm{c}$ $T_{\text {carb }}=1600^{\circ} \mathrm{C}[22]$.

Поскольку по данным рентгеноструктурного анализа (рис. 1) в интервале $850<T_{\text {carb }}<1000^{\circ} \mathrm{C}$ еще не формируется объемная графитовая фаза, рост $E$ и падение $\delta$ с увеличением $T_{\text {carb }}$ у образцов $\mathrm{BE}-\mathrm{C}(\mathrm{Fe})$ в этом температурном интервале, как и у систем BE-C и BE$\mathrm{C}(\mathrm{Ni})$, связаны, по-видимому, с растущей нанокристаллической фазой в аморфной матрице. Примечательно, что у образцов $\mathrm{BE}-\mathrm{C}(\mathrm{Fe})$ с $T_{\text {carb }}=1000-1150^{\circ} \mathrm{C}$, обладающих наибольшей площадью свободной поверхности и поэтому наиболее перспективных для потенциального использования в качестве электродов для суперконденсаторов [17], наблюдается максимальное значение модуля упругости $E \sim 12 \mathrm{GPa}$, превышающее примерно в 1.5 раза таковое для образцов системы $\mathrm{BE}-\mathrm{C}(\mathrm{Ni})$. Это, по-видимому, объясняется тем, что использование $\mathrm{Fe}$ содержащего катализатора при $T_{\text {carb }}<1000^{\circ} \mathrm{C}$ способствует формированию более упорядоченной нанокристаллической фазы. Оценки размеров нанокристаллитов в образцах $\mathrm{BE}-\mathrm{C}(\mathrm{Fe})$ с $T_{\text {carb }}=1000^{\circ} \mathrm{C}$, сделанные в [22], дают для размеров нанокристаллитов значения $\sim 110 \AA$, 


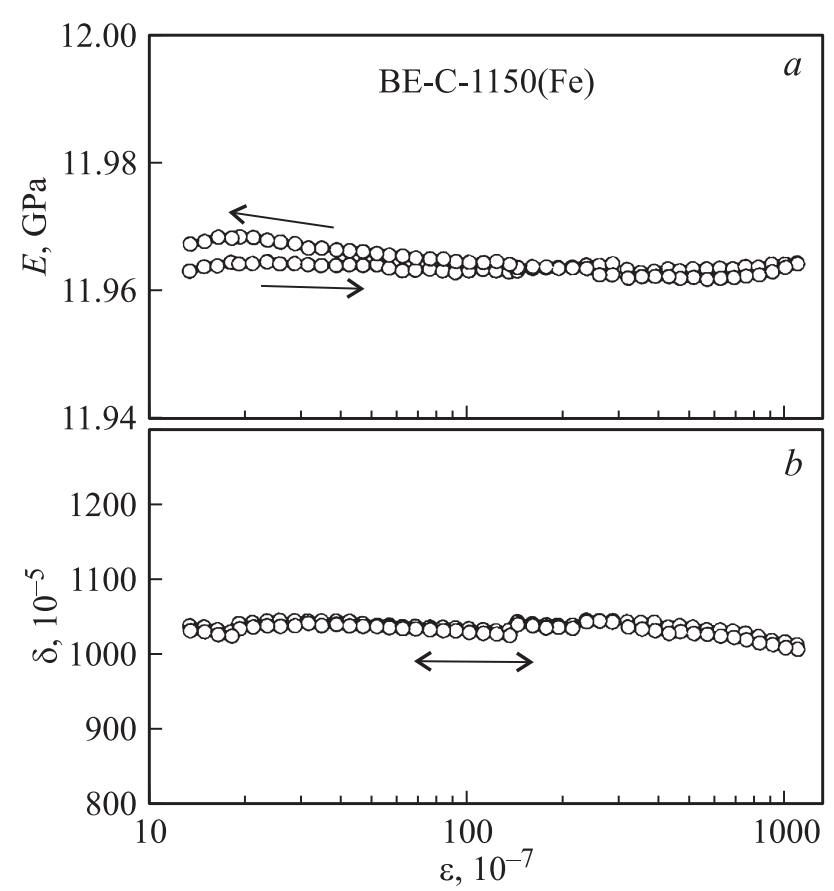

Рис. 4. Амплитудные зависимости модуля Юнга $E(a)$ и декремента $\delta(b)$ для образцов $\mathrm{BE}-\mathrm{C}(\mathrm{Fe})$, полученных при $T_{\text {carb }}=1150^{\circ} \mathrm{C}$ в присутствии Fе-катализатора. Измерения выполнены в вакууме на образцах, подвергавшихся воздействию высоких амплитуд при комнатной температуре. Стрелки указывают направление изменения $\varepsilon$.

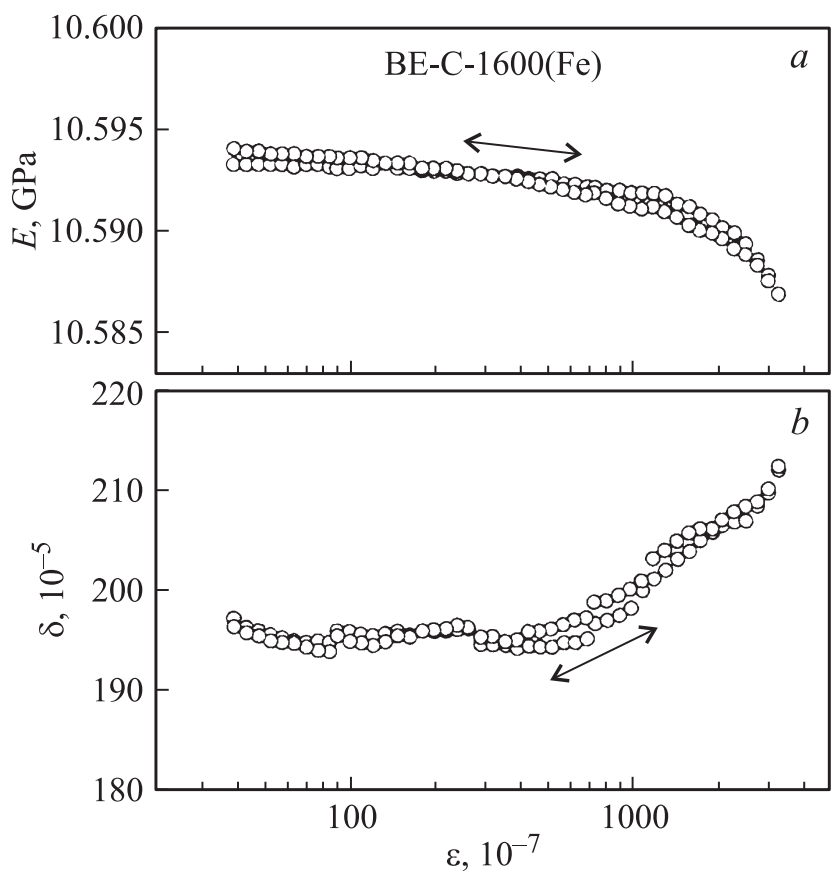

Рис. 5. Амплитудные зависимости модуля Юнга $E(a)$ и декремента $\delta(b)$ для образцов $\mathrm{BE}-\mathrm{C}(\mathrm{Fe})$, полученных при $T_{\text {carb }}=1600^{\circ} \mathrm{C}$ в присутствии Fе-катализатора. Измерения выполнены в вакууме на образцах, подвергавшихся воздействию высоких амплитуд при комнатной температуре. что существенно превышает таковые $(12-26 \AA)$ в образцах $\mathrm{BE}-\mathrm{C}$ с $T_{\text {carb }}=1000^{\circ} \mathrm{C}[29]$.

Для образцов $\mathrm{BE}-\mathrm{C}(\mathrm{Fe})$ было проведено исследование амплитудных зависимостей модуля Юнга $E(\varepsilon)$ и декремента $\delta(\varepsilon)$ для различных температурных областей: $T_{\text {carb }}<1000^{\circ} \mathrm{C}, 1000 \leq T_{\text {carb }}<1300^{\circ} \mathrm{C}$ и $T_{\text {carb }}>1300^{\circ} \mathrm{C}$. На рис. 4 и 5 представлены зависимости $E(\varepsilon)$ и $\delta(\varepsilon)$ для образцов $\mathrm{BE}-\mathrm{C}-1150(\mathrm{Fe})$ и $\mathrm{BE}-\mathrm{C}-1600(\mathrm{Fe})$ соответственно. В области $1000<T_{\text {carb }}<1300^{\circ} \mathrm{C}$ значения модуля $E$ и декремента $\delta$ практически не изменяются при увеличении амплитуды колебаний до значений, превышающих $10^{-4}$, как видно из рис. 4 на примере образца $\mathrm{BE}-\mathrm{C}-1150(\mathrm{Fe})$. Это свидетельствует о пониженной пластичности данных образцов. Эффект пластичности (падение $E$ и рост $\delta$ с увеличением $\varepsilon$ ) у биоуглеродов системы $\mathrm{BE}-\mathrm{C}(\mathrm{Fe})$ начинает проявляться лишь при дальнейшем увеличении $T_{\text {carb }}$ от $1300^{\circ} \mathrm{C}$ (рис. 5). Подобное поведение также демонстрировали образцы $\mathrm{BE}-\mathrm{C}(\mathrm{Ni})$, карбонизированные с использованием $\mathrm{Ni}$-содержащего катализатора. Следует отметить, что в образцах ВЕ-С, полученных без использования катализатора, эффект пластичности проявляется начиная с $T_{\text {carb }}=1000^{\circ} \mathrm{C}$, когда формируется квазиперколяционная структура из нанокристаллитов [30] и поведение упругих и неупругих свойств определяется этой нанокристаллической фазой [24]. Поскольку в образцах $\mathrm{BE}-\mathrm{C}(\mathrm{Fe})$ эффект пластичности (падение $E$ и рост $\delta$ с увеличением $\varepsilon$ ) проявляется начиная с $T_{\text {carb }}>1300^{\circ} \mathrm{C}$, когда происходит быстрый рост объема графитовой фазы: от 30vol.\% при $T_{\text {carb }}=1300^{\circ} \mathrm{C}$ до $\sim 60$ vol. $\%$ при $T_{\text {carb }}=1600^{\circ} \mathrm{C}$ по данным рамановской спектроскопии [22], по-видимому, в этих образцах сформировавшаяся $G$-фаза и контролирует поведение их упругих и неупругих свойств. Обычно амплитудно-зависимое внутреннее трение связывается со скольжением дислокаций, обеспечивающим пластическое течение, которое, несомненно, легче осуществить в кристаллической структуре, чем в аморфной фазе, даже если $G$-фаза в биоуглеродах системы $\mathrm{BE}-\mathrm{C}(\mathrm{Fe})$ состоит из кристаллитов графитовых образований с размерами, не превышающими $200 \mathrm{~nm}$ при максимальной температуре $T_{\text {carb }}=1600^{\circ} \mathrm{C}$, и представляет собой сильно разупорядоченную структуру.

Таким образом, у исследованных в настоящей работе частично графитизированных биоуглеродных матриц $\mathrm{BE}-\mathrm{C}(\mathrm{Fe})$ микропластическая деформация проявляется лишь при $T \geq 1300^{\circ} \mathrm{C}$. Подобное поведение также демонстрировали частично графитизированные биоуглероды системы BE-C(Ni), исследованные ранее [26]. На основе полученных зависимостей $E(\varepsilon)$ были построены диаграммы напряжение $\sigma$-микропластическая деформация $\varepsilon_{d}$ для образцов системы $\mathrm{BE}-\mathrm{C}(\mathrm{Fe})$ (рис. 6). Процедура построения подобных диаграмм описана в [31]. Видно, что образцы $\mathrm{BE}-\mathrm{C}(\mathrm{Fe})$ с $T_{\text {carb }} \geq 1300^{\circ} \mathrm{C}$ имеют меньшие значения условного предела микротекучести $\sigma_{y}$ (напряжение при $\varepsilon_{d}=1.0 \cdot 10^{-8}$ ) по сравнению с образцами с $T_{\text {carb }}<1300^{\circ} \mathrm{C}$. Подобное поведение наблюдалось и для системы $\mathrm{BE}-\mathrm{C}(\mathrm{Ni})$. Наиболее вероятно это связано 


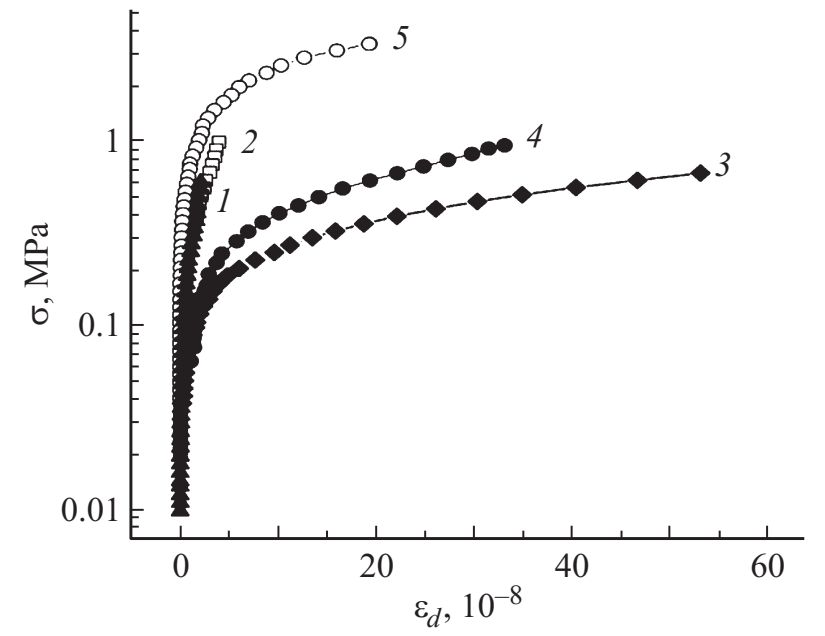

Рис. 6. Кривые напряжение-микропластическая деформация, полученные по данным акустических измерений в вакууме, для образцов $\mathrm{BE}-\mathrm{C}(\mathrm{Fe})$, карбонизированных в присутствии Fе-катализатора. $T_{\text {carb }},{ }^{\circ} \mathrm{C}: 1-850,2-1150,3-1300,4-1400$, $5-1600$.

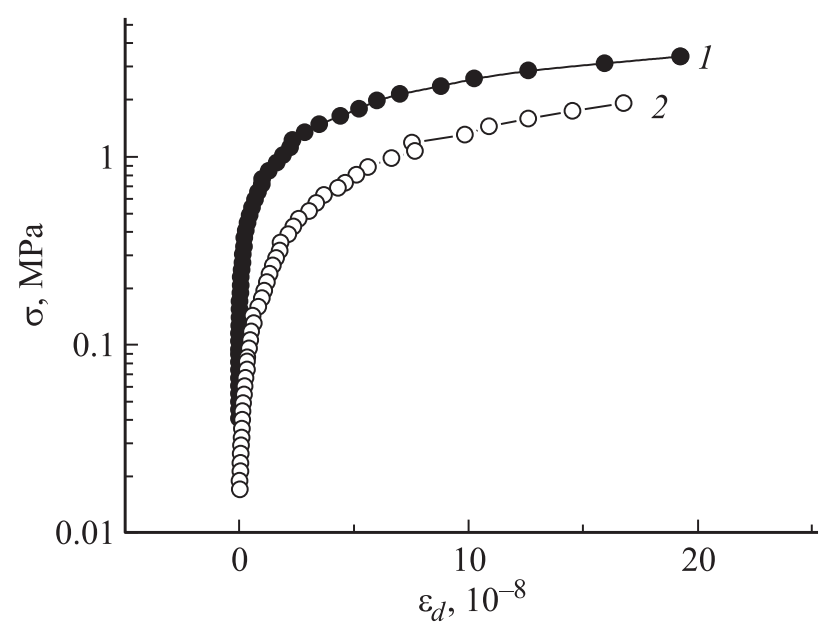

Рис. 7. Сравнение кривых напряжение-микропластическая деформация, полученных по данным акустических измерений в вакууме, для образцов $\mathrm{BE}-\mathrm{C}(\mathrm{Fe})$ и $\mathrm{Be}-\mathrm{C}(\mathrm{Ni})$, карбонизированных при $T_{\text {carb }}=1600^{\circ} \mathrm{C}$ в присутствии Fе-катализатора (кривая 1) и $\mathrm{Ni}$-катализатора (кривая 2 [26]) соответственно.

с формированием значительной объемной доли кристаллитов графитовой фазы при $T_{\text {carb }} \geq 1300^{\circ} \mathrm{C}$. Следует отметить, что у обеих систем $\mathrm{BE}-\mathrm{C}(\mathrm{Fe})$ и $\mathrm{BE}-\mathrm{C}(\mathrm{Ni})$ при возрастании $T_{\text {carb }}$ в области $1300 \leq T_{\text {carb }} \leq 1600^{\circ} \mathrm{C}$ условный предел текучести $\sigma_{y}$ растет, несмотря на то что растут объемная доля графитовой фазы и размер кристаллитов. Казалось бы, более развитая кристаллическая структура должна способствовать облегчению процесса микропластичности, как это наблюдалось, например, для образцов, карбонизированных на основе древесины сосны без катализатора при $T_{\text {carb }}=2400^{\circ} \mathrm{C}$, когда формировалось $\sim 80 \%$ нанокристаллической фазы с размерами кристаллитов 25-60 А [32]. В слу- чае частично графитизированных образцов $\mathrm{BE}-\mathrm{C}(\mathrm{Fe})$ и $\mathrm{BE}-\mathrm{C}(\mathrm{Ni})$, формирующаяся вокруг частиц катализатора графитовая фаза представляет собой совокупность разупорядоченных графитовых структур, выходящих на поверхность. Активация скольжения отдельных дислокаций, по-видимому, и происходит с поверхности образца. Действительно, увеличение $\sigma_{y}$ при повышении $T_{\text {carb }}$ от 1300 до $1600^{\circ} \mathrm{C}$ коррелирует с уменьшением свободной поверхности, образовавшейся за счет введения дополнительной мезопористости при использовании катализаторов. Следует отметить, что сравнение значений $\sigma_{y}$ для двух систем с одинаковой $T_{\text {carb }}$ показывает, что на уровне рассматриваемых деформаций $\varepsilon_{d}=1.0 \cdot 10^{-8}$ микропластическое течение значительно облегчено в системе образцов $\mathrm{BE}-\mathrm{C}(\mathrm{Ni})$ по сравнению с системой $\mathrm{BE}-\mathrm{C}(\mathrm{Fe})$, несмотря на более развитую свободную поверхность в последнем случае. Например, у биоуглерода $\mathrm{BE}-\mathrm{C}-1600(\mathrm{Fe}) \sigma_{y}=0.76 \mathrm{MPa}$, а у биоуглерода $\mathrm{BE}-\mathrm{C}-1600(\mathrm{Ni}) \sigma_{y}=0.18 \mathrm{MPa}$ (рис. 7). Такое различие может быть связано со специфическими особенностями графитовой фазы, выходящей на свободную поверхность при использовании того или иного катализатора.

\section{4. Заключение}

В работе впервые были получены амплитудные зависимости модуля Юнга $E$ и декремента ультразвуковых колебаний $\delta$ для частично графитизированных пористых биоуглеродных матриц, карбонизированных из древесины бука при различных температурах $T_{\text {carb }}$ в присутствии железосодержащего катализатора (система $\mathrm{BE}-\mathrm{C}(\mathrm{Fe})$ ), и проведено сравнение этих характеристик данной системы с таковыми для частично графитизированных образцов, полученных с Ni-содержащим катализатором (система BE-C $(\mathrm{Ni})$ ) и без катализатора (система BE-C).

Методами рентгеноструктурного анализа и электронной микроскопии показано, что присутствие Fе-катализатора при карбонизации приводит к частичной графитизации биоуглеродов при $T_{\text {carb }} \geq 1000^{\circ} \mathrm{C}$, при этом фаза графита формируется в виде наноразмерных полых сферообразных включений, размер которых не превышает $200 \mathrm{~nm}$ даже при максимальном значении $T_{\text {carb }}=1600^{\circ} \mathrm{C}$. Размер графитовых включений и суммарная объемная доля графитовой фазы увеличиваются с повышением $T_{\text {carb. }}$. Полученные для системы $\mathrm{BE}-\mathrm{C}(\mathrm{Fe})$ зависимости $E\left(T_{\text {carb }}\right)$ и $\delta\left(T_{\text {carb }}\right)$ оказались подобными таковым для образцов $\mathrm{BE}-\mathrm{C}(\mathrm{Ni})$ : в интервале $1150<T_{\text {carb }}<1300^{\circ} \mathrm{C}$ наблюдается резкое уменьшение модуля Юнга, сопровождающееся увеличением логарифмического декремента. Величина $E$ увеличивается, а $\delta$ уменышается с повышением $T_{\text {carb }}$ в интервалах $T_{\text {carb }}<1150^{\circ} \mathrm{C}$ и $T_{\text {carb }}>1300^{\circ} \mathrm{C}$, что связывается с формированием в аморфной матрице нанокристаллической фазы в первом и графитовой фазы во втором случае. Резкое падение $E$ и рост $\delta$ в интервале $1150<T_{\text {carb }}<1300^{\circ} \mathrm{C}$ наиболее вероятно свидетельствуют о подавлении формирования нанокристал- 
лической фазы образующейся фазой графита. Пористые биоуглеродные матрицы $\mathrm{BE}-\mathrm{C}(\mathrm{Fe})$ с $T_{\text {carb }}=1000-1150$ и $1600^{\circ} \mathrm{C}$ показывают наиболее высокие значения модуля Юнга, в 1.5-2 раза превышающие значения $E$ для биоуглеродных образцов, полученных с Ni-катализатором и без катализатора.

Неупругая микропластическая деформация (на уровне деформации $1.0 \cdot 10^{-8}$ ) проявляется при повышении температуры карбонизации начиная с $T_{\text {carb }}=1300^{\circ} \mathrm{C}$, при этом величина условного предела микротекучести коррелирует с величиной введенной мезопористости (величиной площади свободной поверхности $A$ ): чем больше $A$, тем ниже значение $\sigma_{y}$.

\section{Список литературы}

[1] L.L. Zhang, X.S. Zhao. Chem. Soc. Rev. 38, 2520 (2009).

[2] E. Frackowiak, F. Beguin. Carbon 39, 937 (2001).

[3] P. Simon, Yu. Gogotsi. Nature Mater. 7, 845 (2008).

[4] M.V. Lebedeva, P.M. Yeletsky, A.B. Ayupov, A.N. Kuznetsov, V.A. Yakovlev, V.N. Parmon. Mater. Renew. Sustain. Energy 4, 20 (2015).

[5] R.K. Gupta, M. Dubey, P. Kharel, Zh. Gu, Q.H. Fan. J. Power Sources 274, 1300 (2015).

[6] A.B. Fuertes, G. Lota, T.A. Centeno, E. Frackowiak. Electrochim. Acta 50, 2799 (2005).

[7] P. Greil, T. Lifka, A. Kaindl. J. Eur. Ceram. Soc. 18, 1961 (1998).

[8] P. Greil. J. Eur. Ceram. Soc. 21, 105 (2001).

[9] V.S. Kaul, K.T. Faber, R. Sepulveda, A.R. de Arellano Lopez, J. Martinez-Fernandez. Mater. Sci. Eng. A 428, 225 (2006).

[10] C. Zollfrank, H. Siber. J. Eur. Ceram. Soc. 24, 495 (2004).

[11] C.E. Byrne, D.C. Nagle. Carbon 35, 267 (1997).

[12] В.В. Попов, Т.С. Орлова, Е. Enrique Magarino, М.А. Bautista, J. Martınez-Fernandez. ФTT 53, 259 (2011).

[13] В.В. Попов, Т.С. Орлова, J. Ramirez-Rico. ФТТ 51, 2118 (2009).

[14] И.А. Смирнов, Б.И. Смирнов, Т.С. Орлова, Cz. Sulkovski, H. Misiorek, A. Jezowski, J. Mucha. ФTT 53, 2133 (2011).

[15] Л.С. Парфеньева, Т.С. Орлова, Н.Ф. Картенко, Б.И. Смирнов, И.А. Смирнов, Н. Misiorek, А. Jezowski, J. Mucha, M.C. Vera. ФTT 53, 2278 (2011).

[16] Н.Ф. Картенко, Т.С. Орлова, Л.С. Парфеньева, Б.И. Смирнов, И.А. Смирнов. ФТТ 56, 2269 (2014).

[17] A. Gutierrez-Pardo, J. Ramirez-Rico, R. Cabezas-Rodriguez, J. Martinez-Fernandez. J. Power Sources 278, 18 (2015).

[18] A. Gutierrez-Pardo. Tesisdoctoral. Universidad de Sevilla, Sevilla, Spain. ES41080.

[19] A. Gutierrez-Pardo, J. Ramirez-Rico, A.R. de Arellano-Lopez, J. Martinez-Fernandez. J. Mater. Sci. 49, 7688 (2014).

[20] M.T. Johnson, K.T. Faber. J. Mater. Res. 26, 18 (2011).

[21] В.В. Попов, Т.С. Орлова, А. Gutierrez-Pardo, J. Ramirez-Rico. ФTT 57, 1703 (2015).

[22] J. Ramirez-Rico, A. Gutierrez-Pardo, J. Martinez-Fernandez, V.V. Popov, T.S. Orlova. Mater. Design 99, 528 (2016).

[23] Т.С. Орлова, Л.С. Парфеньева, Б.И. Смирнов, А. Gutierrez-Pardo, J. Ramirez-Rico. ФTT 58, 200 (2016).

[24] Б.К. Кардашев, Т.С. Орлова, Б.И. Смирнов, A. Gutierrez, J. Ramirez-Rico. ФTT 55, 1771 (2013).
[25] В.В. Шпейзман, Т.С. Орлова, Б.И. Смирнов, А. Gutierrez-Pardo, J. Ramirez-Rico. Mater. Phys. Mech. 21, 200 (2014).

[26] Т.С. Орлова, Б.К. Кардашев, Б.И. Смирнов, А. Gutierrez-Pardo, J. Ramirez-Rico, J. Martinez-Fernandez. ФTT 57, 571 (2015).

[27] В.В. Шпейзман, Т.С. Орлова, Б.И. Смирнов, А. Gutierrez-Pardo, J. Ramirez-Rico, ФTT 58, 685 (2016).

[28] С.П. Никаноров, Б.К. Кардашев. Упругость и дислокационная неупругость кристаллов. Наука, М. (1985). 254 с.

[29] Л.С. Парфеньева, Т.С. Орлова, Н.Ф. Картенко, Н.В. Шаренкова, Б.И. Смирнов, И.А. Смирнов, Н. Misiorek, A. Jezowski, T.E. Wilkes, K.T. Faber. ФTT 52, 1045 (2010).

[30] A.K. Kercher, D.C. Nagle. Carbon 41, 15 (2003).

[31] Б.И. Смирнов, Ю.А. Буренков, Б.К. Кардашев, D. Singh, K.C. Goretta, A.R. de Arellano-Lopez. ФTT 43, 2010 (2001).

[32] Б.К. Кардашев, Т.С. Орлова, Б.И. Смирнов, Т.Е. Wilkes, K.T. Faber. ФТT 51, 2320 (2009). 